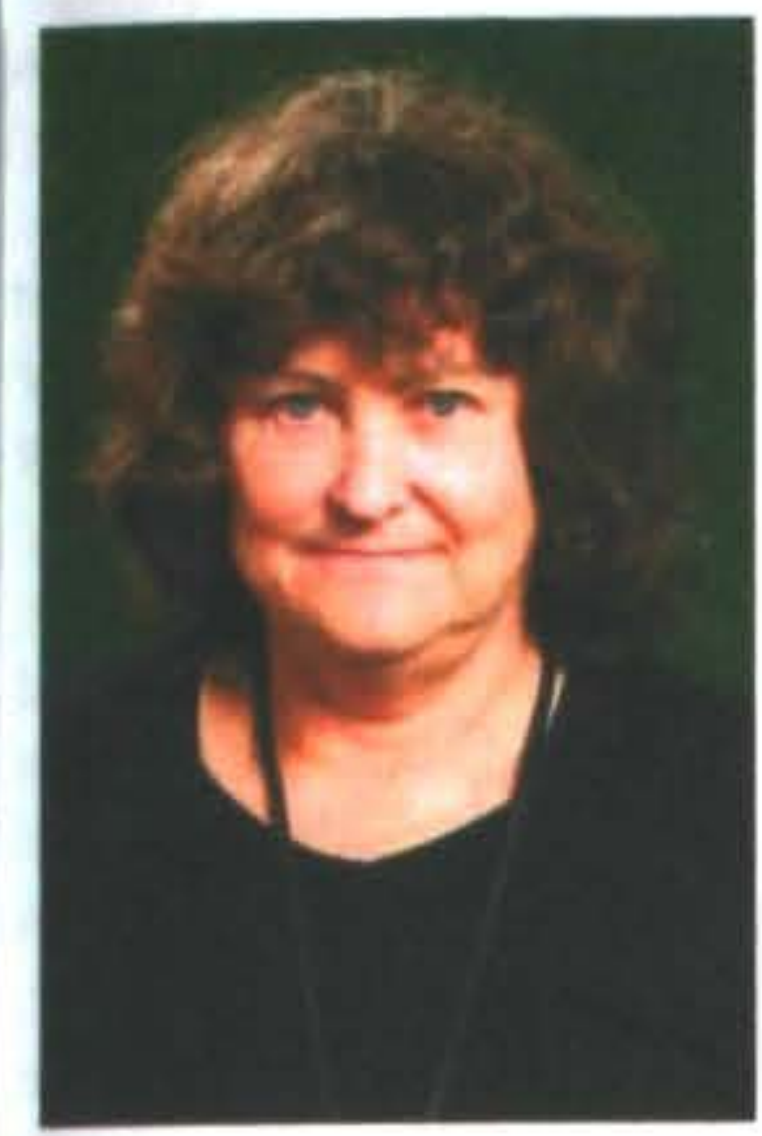

\title{
WORKFORCE DIVERSITY: \\ EVIDENCE OF POSITIVE \\ BUSINESS OUTCOMES AND \\ HOW TO ACHIEVE THEM. A \\ REVIEW OF THE LITERATURE
}

\author{
Mervyl McPherson
}

EEO Trust, Auckland

\begin{abstract}
The demographic diversity of local and global workforces and markets is increasing within what is still generally a context of tight labour market conditions, especially for skilled labour. This paper reviews a wide range of literature on the impact of workforce diversity on business outcomes and how that diversity can be best managed for business success. The review considers various types of diversity, different methodological approaches from quasi-experimental to case studies, and a range of positive business outcomes including improved staff recruitment and retention; improved creativity, innovation and problem solving, improved marketing strategies and outcomes, productivity and net financial returns. Although there are some specific studies or instances that appear to prove the exception to the rule. the consensus from the body of evidence existing to date is that diverse workforces are the reality of the future and that. in general, they have the potential to result in positive enhanced business outcomes. The exceptions are generally explained away as being due to lack of best practice implementation of diversity and equality policies, and management of diverse teams and workforces. This paper. therefore, also investigates the key workplace, management and implementation factors associated with positive versus negative outcomes. We found a lack of research into the links between diversity, workplace practices and business outcomes in the New Zealand context with its large mumber of small businesses, a unique range of ethnic groups and its own cultural norms, signalling the potential for further research.
\end{abstract}

\section{Introduction}

The demographic diversity of local and global workforces and markets is increasing, within what is still generally a context of tight labour market conditions, particularly for skilled labour. As evidence shows that both positive and negative business outcomes can arise from diverse workforces, according to Kochan et al, (2003) and Monks (2007), businesses that learn how to effectively manage diversity will be well placed for competitive advantage in the future

Competitive advantage or business benefits linked to diversity of the workforce include increased profitability, productivity, innovation, and improved sales and marketing outcomes. The potential to increase access to global markets has been identified as important for New Zealand's economic growth (Skilling, 2007a, 2007b; Skilling and Boven, 2006). Skilling also points out that New Zealand needs to attract skills that are not sufficiently available in New Zealand or its traditional source countries.

This paper reviews international literature on the impact of workforce diversity on business outcomes and how that diversity can be best managed for business success.

\section{Debates and definitions}

The focus on workforce diversity developed out of the equal employment opportunities (EEO) approach of the 1970 s, which was based on concepts of human rights, social justice and fairness with the aim of equitable representation of all groups at all levels, and the prevention of discrimination. In contrast, the diversity approach argues that demographic diversity will deliver business benefits to organisations in terms of performance and competitive advantage (Cassell, 2004; CIPD, 2005; Kirton and Greene, 2005). It is this argument that is being put to the test with this review.

The shift from an EEO to a diversity approach occurred throughout the Western world, but coincided in New Zealand with a shift from a legislative approach in the Employment Equity Act of 1990, which was repealed and later replaced with an educative, motivational approach to business through the setting up of the EEO Trust in 1992. As businesses are concerned with bottom-line performance, it was believed that a business-focused approach to encouraging employment of a diverse workforce would be more attractive than one based solely on social responsibility.

However, there is debate in the literature about whether substituting a diversity or business case approach for the traditional equality approach has lost sight of the original 
aims of EEO. A third perspective is that equality and diversity are complementary and both are needed to maximise the benefits of the diverse workforce of the future (Kirton and Greene, 2005). The traditional equality approach is needed to ensure equality of opportunity, but the managing diversity approach builds on this by ensuring difference is valued and harnessed to achieve its potential advantages (Gatrell and Swan, 2008).

A consideration of the impacts of workforce diversity must first identify the type of diversity involved. The research literature covers three main types of diversity: demographic diversity, such as gender, ethnicity or race and age; cognitive diversity or diversity of thinking and values; and functional diversity, which refers to the different job areas such as finance, R\&D, production, sales and marketing etc.

Demographic diversity is the main concern from an EEO perspective, and hence of this paper. While there is obviously some overlap in that different demographic groups may be likely to have different ways of thinking or values, according to Kiefer (2007) and Mannix and Neale (2005) this has not been proven, and there are also cognitive differences within demographic groups, and across functional areas.

\section{Paper structure}

This paper reviews the wide range of research in the broad area of demographic diversity and business outcomes to see what evidence there is to support the claim that a diverse workforce leads to positive business outcomes. Key factors associated with positive or negative outcomes are identified and summarised. The paper concludes with a discussion of what conclusions can be drawn and suggestions for further research. But first, in order to evaluate the evidence presented in the research literature, this paper considers whether it is possible to establish links between diversity and business outcomes and, if so, how this can be done.

\section{Can Links Between Diversity and Business Outcomes be Established?}

It can be argued that it is difficult, if not impossible, to demonstrate a direct link between workforce diversity and equality, and positive business outcomes, because multiple factors impact on business performance. While causality is difficult to prove in any field of research, two main approaches are used to demonstrate a link. One is a quasi-experimental design approach where outcomes for one group (of organisations) is compared with those of another group that is similar in all aspects except the issue being investigated, in this case workforce diversity. This controls for the effect of other influences on business outcomes. The second is the case study approach comparing outcomes before and after an increase in an organisation's workforce diversity, and including evidence on the implementation of the diversity programme in order to be able to link the programme to the outcomes. Results from case studies are context specific and not generalisable to all situations. Both approaches can be found in the diversity research literature.

Most of the research reviewed, however, focuses on just one or two demographic groups, mostly gender and/or ethnicity/race, and some of it is confined to the diversity within management teams.

A wide range of measures of business outcomes is used across the research literature reviewed, but again, most studies only use one or two. These include return on investment (ROI), return on assets, return on equity, net operating profit (linked to reduced costs from turnover, absenteeism), productivity, creativity, market share/penetration, employee engagement /commitment/morale etc. A European Commission review (2003) says there are difficulties in measuring diversity impacts because many of the benefits are context specific, indirect, intangible and qualitative.

To reach a conclusion from such a body of research requires a wide ranging review that includes identification of consistent trends and of factors associated with both positive and negative outcomes.

\section{Evidence of Positive Business Outcomes from a Diverse Workforce}

Overall, a growing body of research supports a link between having and supporting a diverse workforce, including management and boards, and positive business outcomes. While reviews of the evidence often conclude that there have been inconsistent results (Monks, 2007; CIPD, 2005; Kirton \& Greene, 2005), those that examine the differences between positive and negative outcomes generally find empirical support for a link.

\section{Comparisons between high and low diversity organisations}

A number of large studies in the US and UK which compared the business outcomes of organisations that scored highly on diversity practice with those that scored poorly consistently found better business outcomes for the former.

For example, a comparison of 76 US organisations classified as minority-friendly (rated on nine variables such as representation on boards, senior management and total workforce, plus having diversity programmes and other diversity positive practices) with those that rated poorly, found that the minority-friendly organisations achieved higher than average performance in terms of $\mathrm{ROI}$, return on sales and return on equity (Von Bergen et al, 2005).

A UK study based on 140 leading private and public organisations found that $80 \%$ reported a link between good diversity practice and better business performance in terms of improved productivity, better service delivery and cost savings (Rutherford and Ollerearnshaw, 2002:1,10). 
Analysis of the US DiversityInc top 50 companies found links between good diversity practice, retention of minority workers, and better stock performance. The top 10 in the DiversityInc list score from $91-94 \%$ on retention for all ethnic groups and women, compared with around $70-75 \%$ for those in the bottom 10 of the list (DiversityInc, 2006:33-34). DiversityInc's top 50 in 2005 and 2004 also outperformed Standard \& Poor's top 500 companies on stock performance. For the 43 publicly traded companies in the DiversityInc top 50, the return rate was $23.5 \%$ higher than Standard \& Poor's top 500 measured over 10 years with dividends reinvested. Such findings have been replicated by independent researchers such as Slater et al (2008) as seen in Figure 1, Weigand (2007) and Erhardt et al (2003).

Figure 1: Profitability comparison, DiversityInc Top 50 and matched control group of companies, 1998-2003

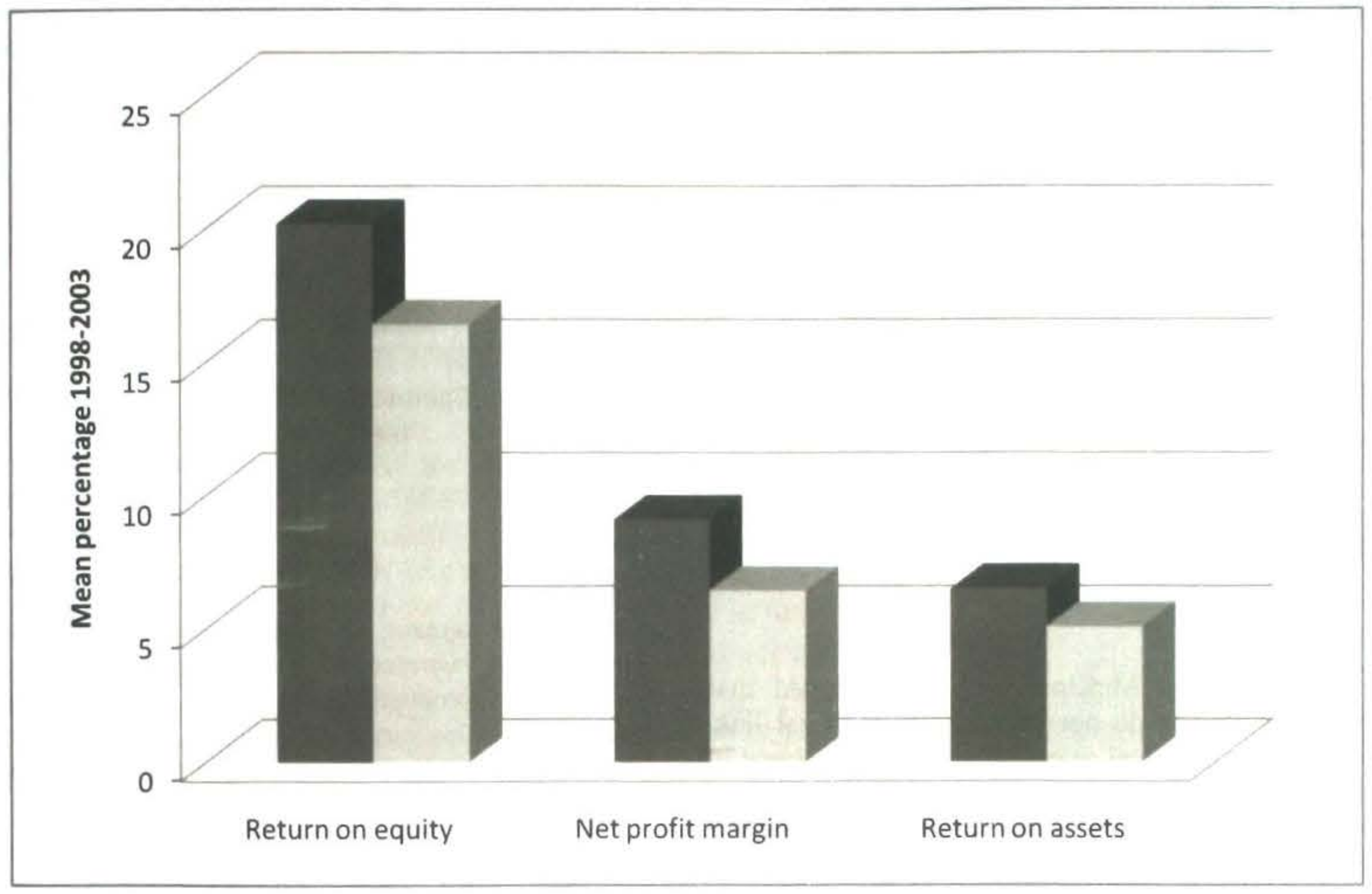

Source: graph created by the author from data in Slater et al, 2008

Some studies were specific to gender (Catalyst, 2004; McKinsey, 2007; Smith et al, 2006) or race (Herring, 2006). Herring's (2006) study of 251 for-profit organisations showed that greater racial diversity was associated with better outcomes in sales revenue, number of customers, market share and profitability. For example, $72 \%$ of those with high racial diversity had greater than average market share and profitability compared with just over $50 \%$ of those with low racial diversity.

A leading study on the relationship between gender diversity in top management teams and financial performance was carried out by Catalyst (2004). This US study used 353 Fortune 500 companies for which sufficient gender diversity and financial performance data were available between 1996 and 2000. Two measures of financial performance were used: return on equity and total return to shareholders. Return on equity was $35 \%$ higher and total return to shareholders $34 \%$ higher in companies with the highest representation of women in their top management teams than those with the lowest female representation. The higher performance of teams with women held true across all the industry groups represented in the study.

These findings were repeated in a study carried out by the international consulting firm McKinsey and Company (2007), as shown in Figure 2. The McKinsey \& Company study also demonstrated that companies with three or more women in senior management scored higher on nine excellence criteria compared with those with fewer than three women. This mirrors other studies showing that the best business outcomes are achieved once a certain level of diversity is reached.

A Danish study of 2500 firms from 1993-2001 also found rigorous statistical evidence of a link between female representation at top executive and board level and performance as measured by gross profit, net sales, contribution margin, operating income and net income after tax. But these outcomes were dependent on the qualifications of the women and the measure of performance used. Gross profit showed a higher positive effect than other measures, and results, which were limited to elected board members, were stronger when the women had a university degree (Smith et al, 2006) 
Figure 2: Economic performance of companies with high gender diversity in management compared with industry average performance

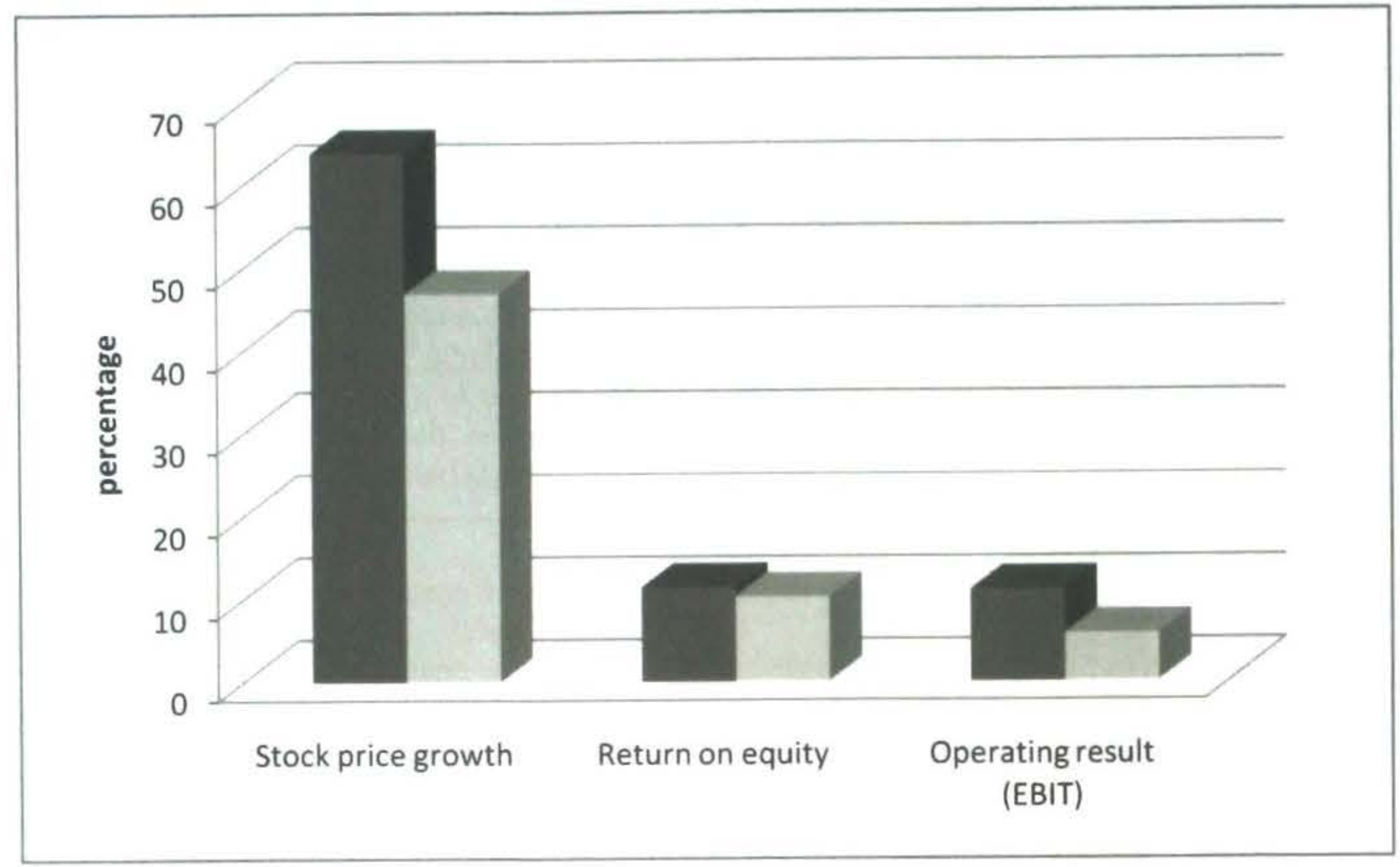

Source: graph created by the author from data in McKinssey \& Co, 2007

\section{Causality}

The authors of the McKinsey report concluded that "while these studies do not demonstrate a causal link, they do give us a factual snapshot that can only argue in favour of greater gender diversity" (2007:14). While acknowledging that a range of factors contribute to business performance outcomes, the converse is that these findings demonstrate a lack of negative trends in performance outcomes associated with increased diversity and policies promoting diversity and equality.

Perotin et al (2003) concluded that both more productive firms and firms that have EEO policies are better managed, as did Bloom et al (2006) in relation to worklife balance and Smith et al (2006) in relation to gender. While these examples suggest a link between a commitment to diversity and good management, some have questioned whether this is purely an association or a causal link and, if so, in which direction. Perotin et al (2003) concluded that the association of EEO and productivity is not a case of reverse causality; that is, that more productive firms are more likely to have EEO policies, as the strength of correlation increased with the number of measures to achieve EEO.

\section{Case study examples of business links to diversity}

Cox (2001) used a case study of a large multinational aluminium producer to demonstrate positive outcomes from his diversity model, which includes leadership, research and measurement, education, alignment of management systems, accountability and follow-up. More than $90 \%$ of his measures of diversity climate showed improvement 18 months after implementation. $\mathrm{He}$ also demonstrated positive relationships between diversity and productivity and work quality, although these relationships varied for different types of diversity. Richard et al (2004) also found different outcomes related to different types of diversity.

Kirton and Greene (2005) gave the example of Procter and Gamble, a large UK-based firm which has a threepronged Diversity Action Plan comprising strategies to attract, develop and retain staff. The initiatives included a training programme which proved to be the most powerful tool in fostering diversity learning and understanding, gender pay equity, achieving good awareness of diversity related policies, outreach to minority ethnic and disabled groups and work-life provisions. After two years, they claimed that this Diversity Action Plan resulted in increased productivity, record breaking sales, high staff morale, high staff retention and enhanced external reputation

Over a 10-year period, leading New Zealand employers have provided statistics and examples in conjunction with their EEO Trust Work \& Life Award entries. Some of this material cannot be published due to business confidentiality, but some examples from the 2007 awards (EEO Trust, 2007) are: a creative approach to recruiting and retaining skilled migrants enabled Beca Transportation to grow by $30 \%$ in one year at a time when similar organisations were losing staff to their competitors in New Zealand and overseas; a positive approach to diversity has resulted in substantial benefits for Mount Albert Pak ' $n$ Save, for example, low staff turnover saves the supermarket approximately $\$ 100,000$ per annum. 


\section{Other methods and approaches}

A range of other research approaches have been used to assess the net business benefits of workforce diversity, from self-report surveys to multi-method approaches. These have been applied across large numbers of organisations but no control group comparison has been made.

Monks (2007) reports on three studies undertaken for the European Commission covering 200, 761 and 3000 organisations to examine the costs and benefits of workforce diversity policies. Using a range of research methods from surveys to case studies, these studies identified four core areas of benefit: human capital, market access, enhanced reputation and employment relations. These are achieved through attracting a wider range of quality staff to address labour shortages, matching the diversity of new markets, and reduced costs from better employment relations.

The European Commission (2003) review of the costs and benefits of diversity policies involved surveying 200 companies in four countries; eight case studies of diversity promotion programmes in six countries, and nearly 50 interviews with key informants from business, government, NGOs, unions and equality agencies. The review found that companies that implement diversity policies identify important benefits that strengthen longterm competitiveness and sometimes result in improved performance in the shorter term. The most frequently identified benefits (by more than half the organisations surveyed) related to enhanced reputation, attraction and retention of highly talented people, improved motivation and efficiency, improved creativity and innovation. enhanced service levels and customer satisfaction, and helping to overcome labour shortages.

Similarly, in Rajan et al's (2003) UK study of 486 companies which had had diversity initiatives for about three years, half reported attracting talent from wider sources, improved employer image and a more innovative workforce with a greater variety of approaches and styles. Forty per cent of the companies reported greater employee commitment, higher productivity, improved customer satisfaction and retention, improved employee retention and an increased range of customers in new markets. A third reported increased sales and/or market penetration.

\section{Creativity and innovation}

Another suggested link between diversity and performance relates to improved innovation and creativity, however, a search of academic databases produced only a dozen articles on the topic from 2001 to 2007. Some were reviews of existing research (BassettJones, 2005; McMillan-Capehart, 2005), while others reported on their own research or experience. Much of the research reviewed in this area also focused more on functional or cognitive diversity than demographic diversity. Some was also limited to subjective assessment rather than rigorous measurement. For example, a CIPD (2005) report shows that around $60 \%$ of companies believed their diversity policies resulted in improved innovation and creativity.

Most of the studies were small and involved only one or two specific measures of diversity and creativity or innovation (EEO Trust, 2008). For example, a study of gender diversity found the optimal balance of men and women for both experimentation and efficiency of teams was 50:50 (Lehman Brothers Centre for Women in Business, 2007:32-33). They are therefore case specific rather than generalisable to all types of diversity and all circumstances, and do not demonstrate a clear, direct relationship between demographic diversity and innovation, creativity, problem solving or decision making.

What they did demonstrate though was that, in order to achieve better outcomes from diverse groups than homogenous groups, organisations need a management style and a workplace and team culture that is open to change and encourages participation by women and minorities (Bassett-Jones, 2005; Cox, 2001; Lattimer, 1998; Hubbard, 2004; de Dreu and West, 2001). For example, de Dreu and West (2001) found that minority dissent was associated with team innovation only when there were high levels of participation in decision making by team members, along with low resistance to change.

\section{Factors influencing business outcomes of diversity}

\section{Barriers to positive outcomes - communication and conflict.}

Common negative outcomes or problems encountered in working with diverse teams and workforces are conflict, poor communication and greater length of time to arrive at solutions (CIPD, 2005; Monks, 2007). Mannix and Neale (2005) conclude that demographic diversity has an inherently negative effect on group functioning unless the group process is carefully controlled for communication and conflict management.

Communication and understanding cultural differences around communication are the most significant factors according to several researchers (Gassmann, 2001; Cox , 2001; Kiefer, 2007; McMillan-Capehart, 2005). Hubbard (2004) found that diverse teams generated more ideas that evolved into products and services than homogenous teams. Despite homogenous teams starting with better communication due to shared frames of reference, relating and values, these same commonalities limit their output. But he also concluded that diverse team members need to understand each other's differences in order to overcome conflict and misunderstanding and work effectively together.

Conflict can be a barrier to collaboration when different people work together. However, rather than avoid or eliminate it, conflict requires effective, constructive management "to transform it from a major liability into a significant asset" (Weiss and Hughes, 2005:94). Kiefer (2007) identifies two types of conflict related to diversity. 
Positive or constructive conflict is conflict of ideas and ways of doing things that ultimately leads to better solutions or outcomes. Negative conflict is conflict of emotions, personalities and relationships that needs to be managed so as not to get in the way of the potential benefits arising from diversity of thought, values, experiences and perceptions.

However, absence of conflict as a result of pressure to conform can result in "group think", where norms are established and adhered to in order to keep things comfortable and "outsiders are ignored and deviant ideas or behaviours disregarded or punished" (Kiefer, 2007: p. 28 ), thus eliminating the positive benefits of diversity. Furthermore, those who feel forced to adapt to fit the norm are likely to leave the organisation (McMillanCapehart, 2005).

\section{Explaining negative outcomes - management style and workplace culture}

"The approach to diversity and not the diversity itself determines the actual positive and negative outcomes". (Lane \& Di Stefano, 1992, cited in Gassmann, 2001).

Cox (2001) said the main reason for poor management of diverse workforces relate to interpreting diversity as employing demographically different people who are expected to fit the norms of the existing workplace culture, rather than recognising, valuing, encouraging and rewarding difference. Traditional management styles that look for and encourage cultural fit can thus lead to high turnover of people who are different rather than making good use of their difference (Thomas, 2006; McKay and Avery, 2005).

Lattimer (1998) also found that strong pressure to conform to existing norms and ways of doing things alienates those who are different and thereby loses the value of their different perspective, frequently causing them to leave the organisation. Lattimer also identifies, along with others such as McMillan-Capehart (2005), Gassmann (2001) and (Smith, 1999), the need for recognition and appreciation of different values so that individuals are encouraged to express their differences within a context of a focus on shared team goals to achieve better outcomes.

\section{Threshold level}

A number of studies showed that the best business outcomes are achieved once a certain level of diversity is reached. Roberson and Park's (2007) study of the relationship between the racial diversity of top management and financial performance in Fortune 500 top diversity companies showed that low levels of racial diversity (up to $22 \%$ ) are associated with declines in financial performance but, as racial diversity increases, financial performance improves. They suggested that at low levels of racial diversity, true diversity practice is not encouraged. Similarly, McKinsey and Company (2007) demonstrated that companies with three or more women in senior management scored higher on nine excellence criteria compared with those with fewer than three women.

The degree of diversity has also been shown to affect the links between diversity and innovation or creativity. Richard et al (2004) examined racial and gender diversity in relation to performance in the US banking sector in terms of innovation and productivity, finding that the relationship was complex and non-linear. The researchers investigated the optimum level of heterogeneity needed to maximise the benefit of diverse perspectives and minimise negative outcomes. Innovation and productivity increased once racial diversity of management was over 0.25 , and different levels of gender diversity were related to different positive outcomes.

\section{Achieving Positive Outcomes from Diversity}

\begin{abstract}
"There is a crucial distinction between merely having diversity in the workforce and developing the organisational capacity to leverage diversity as a resource. The challenge of diversity is not simply to have it, but to create conditions in which its potential to be a performance barrier is minimized and its potential to enhance performance is maximized." (Cox, 2001:15-16)
\end{abstract}

Simmons and Weathers (2007) noted that celebrating diversity only as a positive ignores real problems that must be solved, as outlined above. The key focus now, they say, needs to be on providing information on how to deal with differences in a constructive way which helps harness the potential benefits.

Successful outcomes from workforce diversity depend on how policies and practices are implemented, with supportive management and workplace culture identified as critical factors. Key steps include commitment and leadership by senior management; manager accountability; measurement of progress; integration and targeting to specific business aims; support networks; mentoring for women, minorities, and any other underrepresented groups, and practical behavioural based training (CIPD, 2005; Rajan, 2003; Rutherford \& Ollearenshaw, 2002; Layne, 2002; Hyter \& Turnock, 2005; Opportunity Now, 2004; McKay \& Avery, 2005; Watts \& Trlin, 2000; Mor-Barak, 2005; Kochan et al, 2002; Catalyst, 2002b).

In addition, a combination of diversity policies and practices is needed for effective diversity management. According to Richard and Johnson (2001:3), "Simply one or two activities in support of diversity fails to constitute a diversity orientation. Rather, these activities must work together and reinforce one another". Rutherford and Ollerearnshaw's (2002:2) research on 140 leading UK organisations found that taking a comprehensive approach for two years has as much or more effect than 20 years of piecemeal change.

Successful outcomes also depend on integrating diversity policies into the overall organisational strategy and 
culture rather than leaving diversity implementation to HR departments and line managers (Monks 2007; MorBarak, 2005; Rutherford \& Ollerearnshaw, 2002; Rajan et al, 2003; Cox, 2001). Cox (2001:26) describes the process as looking at each of these areas "through the lens of diversity" to see how they might better reflect the demands and potential of a diverse workforce.

\section{Culture and management change}

Leonard and Swap (1999) conclude that "it takes more than demographic or ethnic diversity to result in creativity that leads companies to perform better". According to Leonard and Swap, in order to spark creativity and innovation, special management skills are required to overcome conflict and provide toleration and support for dissent. Process rules and communication skills are also needed, as well as an organisational culture that is conducive to maximising a team's ability to think divergently.

Similarly, Bassett-Jones (2005) found that new management styles are needed to achieve positive outcomes from workforce diversity. Successful diversity management, according to CIPD (2005), involves a culture shift in management style from controlling to trusting, which in turn involves a shift from focusing on inputs and processes (time in office, traditional ways of doing things) to outcomes.

These views echo Lattimer (1998:5) who concluded that "diverse groups and teams significantly outperform their homogenous counterparts, especially in problem-solving and decision-making" and that the concerns and reservations about the efficiency of diverse work teams are "greatly exaggerated". But in order to capitalise on the benefits of diverse perspectives and ways of working, initial issues of trust and communication need to be professionally facilitated and worked through.

The need for workplace culture change so that diversity initiatives can be effective has been emphasised by many other researchers and reviewers (Kirton \& Greene, 2005; Thomas \& Ely, 2005; Sinclair, 2006). In New Zealand, Watts and Trlin (2000) researched over 300 private sector companies and government organisations on the employment of immigrants from non-English speaking backgrounds, finding that the key factors in productive diversity were recognition of the reality of diversity, viewing that diversity as an advantage, assisting with positive settlement, and establishing a workplace culture that fosters productive diversity.

Diversity initiatives without a supporting infrastructure result in failure and consequent resistance. From her review of the evidence on workplace diversity and equality, Monks (2007) identified the three key characteristics of inclusive workplace cultures as being freedom from discrimination, valuing diversity, and proactively pursuing equality. These characteristics need to be demonstrated through a set of consistent policies which are supported by organisational practices at all levels.
McMillan-Capehart's (2005) review concluded that to benefit from the positive outcomes of diversity and reduce the negative, organisations need to appreciate individual difference while emphasising cooperation and shared purpose or goals.

\section{Management commitment, accountability and training}

Kirton and Greene (2005) noted that, because of the unequal representation of certain groups of employees in management, line managers and senior managers tend to be disproportionately from the dominant group, which makes implementation of a diversity and equality policy inherently problematic. For example, they cited a study that found that line managers generally perceive disabled employees as a problem or burden. In a New Zealand example, the EEO Trust (2007b) employee engagement survey found that managers had more positive perspectives of their workplace culture and initiatives than staff did. To overcome this, senior managers need to be convinced of the benefits of effective diversity management, and line managers need to be made accountable for implementing and achieving it, and provided with appropriate training and support (Kirton and Greene, 2005; Monks, 2007; Schmidt, 2007; Simmons \& Weathers, 2007).

Line managers have been identified as being critical to the success of diversity policies. (Monks, 2007; McPherson, 2006; Kirton \& Greene, 2005). Research into why managers are unsupportive identifies lack of knowledge, training and support, together with underresourcing for any short-term costs. Drawing on research on 500 UK companies with diversity initiatives, Rajan et al (2002) identified that barriers to managers implementing diversity policies included time pressures and other perceived priorities, attitudes and inexperience in dealing with diversity, and a culture of face time and long hours. Similar problems were found by Wentling (2004), and Mor-Barak (2005), who recommended training for managers alongside accountability.

Cox (2001) cited case studies comparing diverse and homogenous groups, with and without diversity training, and found that diversity training and proactive management determined whether diverse groups outperformed homogenous groups on problem solving tasks. Smith (1999:12) pointed out that training needs to go beyond increasing awareness of diversity to developing the skills needed "to resolve group conflict and engage in effective problem solving and decision making with diverse groups".

\section{Measurement and evaluation}

Monitoring of progress and outcomes is essential for accountability. The importance of measuring the success of diversity initiatives is agreed on by all the writers in this field. Monks (2007) identified three key functions of diversity and equality measurement: measurement of an activity drives action (what gets measured gets done), measurement is necessary to justify costs, and 
measurement is necessary to monitor progress on goals and benchmarks. A fourth, noted by the European Commission (2003) review, is to learn what works and why in order to drive investment decisions in the future.

\section{Conclusions}

The many difficulties involved in undertaking robust research into the links between diversity and business outcomes mean there may never be more reliable research than what exists now. All research has limitations. Drawing conclusions involves summing up the consistency of trends across a large body of research, and deriving sound explanations for those that are inconsistent. Hence, the conclusions drawn from this review are that, although there are some specific studies or instances that prove the exception to the rule, the consensus from the body of evidence existing to date is that diverse workforces are the reality of the future and that, in general, they have the potential to result in positive business outcomes. The exceptions are generally explained away as being due to lack of best practice implementation of diversity and equality policies and management of diverse teams and workforces.

Reviews of studies across large numbers of organisations are consistent in the key factors identified as being associated with positive business outcomes. These are: leadership commitment; culture and management change; training and communication; measurement and accountability.

Most studies on the outcomes of demographic diversity in the workplace have related to gender or ethnicity/race. None include disability, yet it could be argued the experience of living with a disability provides a different perspective in the same way as other diversity characteristics do.

There is also a lack of New Zealand research into the links between diversity and equality and positive business outcomes, taking into account the New Zealand policy environment: the comparatively small size of most New Zealand organisations; the specific ethnic groups and cultural context: and cultural norms regarding paid work and family life.

New Zealand business school academic Pringle (Pringle et al, 2006) concluded, along with Kirton and Greene (2005) in the UK, that there is a need for national and culture specific organisational research on diversity, rather than relying on US dominant material and experience. They recommend a multi-method approach to diversity research within organisational contexts. This is in line with the European Commission review which recommended that governments play a role in providing information on workplace diversity issues, particularly in the form of case study experience of organisations that have invested in diversity policies.

\section{Note}

1 A guide to measuring diversity outcomes is available in the appendix of the EEO Trust (2008) review of the positive business outcomes of diversity and equality and how to achieve them.

\section{References}

Bassett-Jones, N. (2005). The paradox of diversity management, creativity and innovation. Creativity and Innovation Management, 14(2):169-175.

Bloom, N., Kretschmer, T., and van Reenen, J., (2006). Work life balance, management practices and productivity. Centre for Economic Performance, London School of Economics. www.lse.ac.uk.

Cassell, C. (2004). The business case and the management of diversity. In Women in Management. Current research issues volume II. Davidson, M. and Burke, R. (eds). Sage:250-262.

Catalyst (2004). The bottom line: connecting corporate performance and gender diversity. Catalyst, www.catalystwomen.org.

Catalyst (2002b). Making change; assessing your work environment. Catalyst, New York, www.catalystwomen.org

CIPD (2005). Managing diversity. Linking theory and practice to business performance. Chartered Institute of Personnel and Development, London.

Cox, T. (2001). Creating the multicultural organisation. A strategy for capturing the power of diversity. University of Michigan Business School Management Series.

De Dreu, C. and West, M. (2001). Minority dissent and team innovation: the importance of participation in decision making. Journal of Applied Psychology, 86(6):1191-1201.

DiversityInc (2006). The business case for diversity. Based on best practices from the nation's leading data-driven diversity list: the DiversityInc Top 50 Companies for Diversity. $5^{\text {th }}$ edition. DiversityInc. www.DiversityInc.com.

EEO Trust (2008). Diversity and equality - evidence of positive business outcomes and how to achieve them. A review of the literature.

http://www.eeotrust.org.nz/research/index.cfm

EEO Trust (2007a). The way we work and live in 2007, EEO Trust Work Life Awards 2007.

http://www.eeotrust.org.nz/awards/leaders.cfm

EEO Trust (2007b). Work-life balance, workplace culture and employee engagement survey report 2007 and Work-life balance, employee 
engagement and discretionary effort: a review of the evidence. www.eeotrust.org, New Zealand.

Erharadt, N., Werbel, J. and Shrader, C. (2003). Board of director diversity and firm financial performance. Corporate Governance, 11(2):102111.

European Commission (2003). The costs and benefits of diversity. A study on methods and indicators to measure the cost-effectiveness of diversity policies in enterprises. Executive summary.

http://europa.eu.int/comm/employment

social/fundamental rights/prog/studies en.htm

Gassmann, O. (2001). Multicultural teams: increasing creativity and innovation by diversity. Creativity and Innovation Management, 10(2): 88-95.

Gatrell, C and Swan, E. (2008). Gender and diversity in management. A concise introduction. Sage.

Herring, C. (2006). Does diversity pay? Racial composition of firms and the business case for diversity. Dept of Sociology and Institute of Government and Public Affairs, University of Illinois, Chicago.

Hubbard, E. E. (2004). The diversity scorecard. Evaluating the impact of diversity on organisational performance. Elsevier

Hyter, M. and Turnock, J. (2005). The power of inclusion. Unlock the potential and productivity of your workforce. Wiley, Canada.

Ivanecevich, J.M. and Gilbert, J.A. (2000). Diversity management. Public Personnel Management, 29(1):75-93.

Kalev, A., Dobbin, F., and Kelly, E. (2006). Best practices or best guesses? Assessing the efficacy of corporate affirmative action and diversity policies. American Sociological Review, 71:589617.

Kiefer, S. (2007). Top management team diversity and firm performance. Investigating German companies. VDM verlag, www.vdm-verlag.de.

Kirton, G. and Greene, A. (2005). The dynamics of managing diversity. A critical approach. $2^{\text {nd }}$ edn. Elsevier.

Kochan, T. et al. (2003). The effects of diversity on business performance: report of the diversity research network. Human Resource Management, 42(1):3-21.

Lattimer, R. (1998). The case for diversity in global business, and the impact of diversity on team performance. Competitiveness Review, 8(2):3-17.
Layne, P. (2002). Best practices in managing diversity. Leadership and Management in Engineering, October, 28-30.

Lehman Brothers Centre for Women in Business, (2007). Innovative potential: men and women in teams, London Business School, London:32-33.

Leonard, D. and Swap, W. (1999), When sparks fly. Igniting creativity in groups. Harvard Business School Press, Boston.

McKay, P.F. and Avery D.R., (2005). Warning! Diversity recruitment could backfire. Journal of Management Inquiry, 14(4):330-336.

McKinsey and Company, (2007). Women matter. Gender diversity, a corporate performance driver. McKinsey \& Company.

McLeod, P., Lobel, S. and Cox, T. (1996). Ethnic diversity and creativity in small groups. Small Group Research, 27(2):248-264.

McMillan-Capehart, A. (2004). A configurational framework for diversity: socialization and culture. Personnel Review, 34(4):488-503.

McPherson, M. (2008). The role of managers in worklife balance implementation. Proceedings of Labour, Employment and Work $12^{\text {th }}$ conference, Victoria University, Wellington, November 2006. www.victoria.ac.nz/geo/news-andevents/lew12/Lew12Papers.html.

Mannix, E. and Neale, M. (2005). What differences make a difference? The promise and reality of diverse teams in organisations. Psychological Science in the Public Interest, 6(2):31-55.

Mercer, G. (2005). Job retention: a new policy priority for disabled people. In Working Futures? Disabled people, policy and social inclusion. Roulstone, A. and Barnes, C. (eds), Policy Press, University of Bristol, Bristol.

Monks, K. (2007). The business impact of equality and diversity. The international evidence. The Equality Authority, Dublin.

Mor-Barak, M.E. (2005). Managing diversity. Toward a globally inclusive workplace. Sage, Thousand Oaks. July, 16(7):1195-1210.

Opportunity Now (2004). Diversity dimensions integration into organisational culture. Opportunity Now, London.

Perotin, V., Robinson, A. and Loundes, J. (2003). Equal opportunities practices and enterprise performance: a comparative investigation on Australian and British data. International Labour Review, 142(4):471-506. 
Pringle, J., Konrad, A. and Prasad, P. (2006). Conclusion, reflection and future direction. In Understanding and Managing Diversity. Readings, cases and exercises. $3^{\text {rd }}$ edn. Harvey and Allard (eds), Pearson/Prentice Hall, N.J.

Rajan, A., Martin, B. and Latham, J. (2003), Harnessing workforce diversity to raise the bottom line. Create, Tunbridge Wells.

Richard, O., Barnett, T., Dwyer, S. and Chadwick, K. (2004). Cultural diversity in management, firm performance, and the moderating role of entrepreneurial orientation dimensions. Academy of Management Journal, 47(2):255-266.

Richard, O. C. and Johnson, N. B. (2001). Understanding the impact of human resource diversity practices on firm performance, Journal of Managerial Issues, 13(2):177-196.

Roberson, Q. and Park, H. (2007). Examining the link between diversity and firm performance: the effects of diversity reputation and leader racial diversity. Group Organisation Management, 32(548-568).

Rutherford, S. and Ollerearnshaw, S. (2002). The business of diversity. How organisations in the public and private sectors are integrating equality and diversity to enhance business performance. Schneider-Ross.

Schmidt, L. (2007). Different strokes. Afrboss magazine, November. www.afrboss.com.au.

Simmons, C. and Weathers, R. (2007). How a smart diversity strategy can help win the talent war. View, issue 6. PriceWaterhouseCooper.

Sinclair, A. (2006). Critical diversity management practice in Australia: romanced or co-opted? In Handbook of Workplace Diversity. Konrad. Prasad and Pringle (eds), Sage.

Skilling, D. (2007a). Achieving long-term economic success in Asia. New Zealand Institute, July 2007. www. New Zealandinstitute.org.

Skilling, D. (2007b). Creating a weightless economy; positioning New Zealand to compete in the global economy. New Zealand Institute, September 2007. www. NewZealandinstitute.org.

Skilling, D. and Boven, D. (2006). The flight of the Kiwi: going global from the end of theworld. Executive summary 2006/1. www.NewZealandinstitute.org.

Slater, S., Weigand, R. and Zwirlein, T. (2008). The business case for commitment to diversity. Business Horizons, 51. 201-209.
Smith, D. (1999). What is the bottom-line impact of diversity? Linkage Research

Smith, N., Smith, V. and Verner, M. (2006). Do women in top management affect firm performance? A panel study of 2,500 Danish firms. International Journal of Productivity and Performance Management, 55(7):569-593.

Thomas, R.R., (2006). Building on the promise of diversity. How can we move to the next level in our workplaces, our communities and our society? Amacom, US.

Thomas, D. and Ely, R. (2005). Making differences matter: a new paradigm for managing diversity. In Understanding and Managing Diversity. Readings, cases and exercises. $3^{\text {rd }}$ edn. Harvey and Allard (eds), Pearson/Prentice Hall, N.J.

Von Bergen, C., Soper, B., Parnell, J. (2005). Workforce diversity and organisational performance. Equal Opportunities International, $24(3 / 4): 1-16$

Watts, N. and Trlin, A. (2000). Diversity as a productive resource: employment of immigrants from nonEnglish speaking backgrounds in New Zealand. Social Policy Journal of New Zealand, 15:87-101.

Weigand, R. (2007). Organisational diversity, profits and returns in US firms. Problems and Perspectives in Management, 5(3):69-83.

Weiss, J and Hughes, J. (2005). Want collaboration? Accept and actively manage conflict. Harvard Business Review, March:93-101.

Wentling, R. M., (2004). Factors that assist and barriers that hinder the success of diversity initiatives in multinational corporations. Human Resource Development International. June, 7(2):165-18.

\section{Author}

Mervyl McPherson

Researcher

Equal Employment Opportunities Trust

P.O. Box 12929

Auckland 1642

MMcPherson@eeotrust.org.nz 